\title{
Nationwide Survey on Implementation of 2011 Nuclear Regulatory Commission Policy on Release of Patients After 131I Therapy for Thyroid Cancer
}

\author{
Di Wu ${ }^{1,2}$, Cristiane J. Gomes Lima ${ }^{1,3}$, Gary Bloom ${ }^{4}$, Kenneth D. Burman ${ }^{3}$, Leonard Wartofsky ${ }^{1,3}$, and \\ Douglas Van Nostrand ${ }^{1,2}$ \\ ${ }^{1}$ MedStar Health Research Institute, Hyattsville, Maryland; ${ }^{2}$ Nuclear Medicine Research, MedStar Washington Hospital Center, \\ Washington, District of Columbia; ${ }^{3}$ Division of Endocrinology, MedStar Washington Hospital Center, Washington, District of \\ Columbia; and ${ }^{4}$ ThyCa: Thyroid Cancer Survivors' Association, Inc., New York, New York
}

\begin{abstract}
The objective of this nationwide survey was to evaluate whether there has been a change in the practice regarding hospital release of differentiated thyroid cancer patients treated with ${ }^{131}$ I since the publication of Nuclear Regulatory Commission Regulatory Issue Summary 2011-01 addressing patient release. Methods: A survey was emailed to approximately 25,000 members of ThyCa: Thyroid Cancer Survivors' Association, Inc., and was available online from March to August 2018. Responses were included from adult patients regarding their most recent ${ }^{131}$ I therapy received between 2011 and 2018 ("after 2011"). Responses to this survey were compared with those of a similar previous survey for ${ }^{131}$ I therapies received between 1997 and 2009 ("before 2009"). Results: Of the 2,136 responses, 1,111 met the inclusion criteria. A similar percentage $(\sim 98 \%)$ of patients were given oral or written radiation safety instructions (RSIs) after 2011 and before 2009, with a shift away from nuclear medicine physicians providing instructions after 2011 (43\%) in comparison with before 2009 (54\%; $P<0.001)$. More patients were able to discuss and individualize the RSls after 2011 (67\%) than before 2009 (29\%; $P<0.001)$. However, $2 \%$ of patients do not recall ever receiving RSIs after 2011. After 2011, more patients were treated as outpatients (87\%) than before 2009 (66\%; $P<0.001)$. For outpatients, more patients were discharged within $30 \mathrm{~min}$ after receiving ${ }^{131}$ I therapy after 2011 (78\%) than before 2009 (72\%; $P=0.002)$. The same percentage $(0.6 \%)$ of patients traveled more than $2 \mathrm{~h}$ with at least 2 occupants in the vehicle within approximately $1 \mathrm{~m}$ of the patient after 2011 and before 2009. Immediately after therapy, a similar percentage of patients stayed in a nonprivate residence after 2011 (4\%) and before 2009 (5\%; $P=0.28)$. Of the 27 outpatients released within $30 \mathrm{~min}$ to nonprivate residences, 2 patients received $5.55-11.1$ GBq (150-299 $\mathrm{mCi})$ of ${ }^{131} \mathrm{I}$. Conclusion: This survey suggests that since publication of the Nuclear Regulatory Commission Regulatory Issue Summary 2011-01 on patient release after radioiodine therapy, there have been improvements in some radiation safety practices on release of outpatients, as well as improvements in patient compliance on travel and lodging.
\end{abstract}

\footnotetext{
Received May 2, 2019; revision accepted Aug. 5, 2019.

For correspondence or reprints contact: Douglas Van Nostrand, Nuclear Medicine Research, MedStar Washington Hospital Center, 110 Irving St., N.W., Suite GA60F, Washington, DC 20010.

E-mail: douglas.van.nostrand@medstar.net

Published online Aug. 26, 2019.

COPYRIGHT (C 2020 by the Society of Nuclear Medicine and Molecular Imaging.
}

Key Words: ${ }^{131}$ I therapy; differentiated thyroid cancer; radiation safety; nonprivate residence

J Nucl Med 2020; 61:397-404

DOI: 10.2967/jnumed.119.230730

\section{A} conducted between 2009 and 2010 on differentiated thyroid cancer patients who received ${ }^{131}$ I therapy (1), the Nuclear Regulatory Commission (NRC) issued Regulatory Issue Summary 2011-01 in 2011, which strongly discouraged the release of patients to a location other than a private residence (2). The Regulatory Issue Summary 2011-01 states, "Although 10 CFR 35.75 [Code of Federal Regulations, title 10, part 35.75] does not expressly prohibit the release of a radioactive patient to a location other than private residence, the NRC strongly discourages this practice because it can result in radiation exposures to members of the public for which the licensee may not be able to fully assess compliance with 10 CFR 35.75(a) and may result in doses which are not [as low as reasonably achievable]." However, controversy still exists on release of these patients (3-6).

The objective of this nationwide survey study was to evaluate whether there has been a change in practice on the release of differentiated thyroid cancer patients treated with ${ }^{131} \mathrm{I}$ after the publication of the NRC Regulatory Issue Summary 2011-01.

\section{MATERIALS AND METHODS}

\section{Survey Development}

A survey of 29 core questions (Supplemental Table 1; supplemental materials are available at http://jnm.snmjournals.org) was developed to evaluate the radiation safety instructions (RSIs) given to differentiated thyroid cancer patients for their most recent ${ }^{131}{ }^{1}$ therapy. The survey development team included 2 nuclear medicine physicians, 3 endocrinologists, and 1 professional survey developer. Five individuals completed a trial run of the survey, and subsequent modifications were made to increase survey efficiency. Most questions required a single best answer among multiple choices, and a small number of questions allowed selection of multiple answers when applicable.

The finalized survey was administered through SurveyMonkey, an online survey software program. The SurveyMonkey web link was posted on the ThyCa: Thyroid Cancer Survivors' Association, Inc., website, sent to over 25,000 members of ThyCa, and shared through social media. The survey was open from March to August 2018, and 
all responses were anonymous. To minimize multiple response from each respondent, only 1 response was allowed from 1 electronic device.

On the first day that the survey was open, an outside radiation safety professional suggested 4 additional questions on radiation safety discussion and instructions, and these questions were added to the survey on the second day. Hence, these 4 questions were not available to the first-day respondents but were available to all other respondents. Therefore, the total number of respondents for these 4 questions is lower than the total number of respondents for the survey.

Patient responses were included in this analysis if the patient was at least $18 \mathrm{y}$ old during the most recent ${ }^{131} \mathrm{I}$ therapy administration between 2011 and 2018 ("after 2011") within the United States or its territories. The total number of respondents (denominator) indicated for each question changed when respondents skipped a given question. In addition, "Don't know" and "Don't remember" responses were not included in the final analysis.

The survey responses were compared with a similar previous survey evaluating the period 1997-2009 ("before 2009") by Gomes-Lima et al. (1). The data for 1997-2009 in this article may differ from the original GomesLima et al. publication because the reanalyzed cohort may be different (e.g., age cutoff, limitation to the United States, and limitation to outpatients).

\section{Statistical Analysis}

Continuous variables were compared using the Student $t$ test. Categoric variables were compared using the $\chi^{2}$ test or Fisher exact test. A $P$ value of less than 0.05 was considered statistically significant. All statistical analyses were performed in SPSS (version 17.0; IBM).

The Institutional Review Board at MedStar Health approved this survey study, and the requirement to obtain informed consent was waived.

\section{RESULTS}

Of the 2,136 total respondents, 1,111 were adults with differentiated thyroid cancer who had their most recent ${ }^{131} \mathrm{I}$ therapy between 2011 and 2018 in the United States. Fifty-eight percent $(647 / 1,111)$ of respondents received ${ }^{131} \mathrm{I}$ therapy within $3 \mathrm{y}$ from answering the survey. The 4 subsequently added questions on radiation safety discussion and instructions were available to 570 respondents. Tables 1 and 2 present the demographics and the ${ }^{131} \mathrm{I}$ therapies of the survey respondents (1). Supplemental Figure 1 shows the geographic location of the respondents.

\section{RSIs}

A similar percentage of patients was given oral or written RSIs after 2011 (98\%; 1,073/1,091) and before 2009 (97\%;1,219/1,258), with a shift away from the nuclear medicine physician to a greater number of other types of medical staff providing the oral RSIs after 2011 (43\%; 468/1,084) than before 2009 (54\%; 656/1,225; $P<$ 0.001) (Table 3). After 2011, RSIs were given to $97 \%$ (549/564) of patients before ${ }^{131} \mathrm{I}$ therapy, and more patients were able to discuss and individualize the RSIs after 2011 (67\%; 315/473) than before 2009 (29\%; 356/1,245; $P<0.001$ ). The specific RSIs received by the patients varied widely among the respondents (Table 4). However, $1.6 \%(18 / 1,091)$ of patients do not recall ever receiving RSIs after 2011; this was similar to the $1.5 \%(19 / 1,238)$ before 2009 $(P=0.82)$. Ninety-four percent $(1,034 / 1,105)$ of the respondents believed they were completely compliant with their RSIs after 2011, a percentage that is higher than the $85 \%(1,013 / 1,194)$ before 2009 .

\section{Outpatient Therapies}

After 2011, more patients were treated as outpatients $(87 \%$; 956/1,102) than before $2009(66 \% ; 1,163 / 1,765 ; P<0.001)$. Compared with before 2009 , slightly more patients were involved in a discussion on the choice of an inpatient or outpatient treatment after $2011(13 \%[147 / 1,098]$ vs. $11 \%[141 / 1,248] ; P=0.12)$, and there was no change in the influence of the insurance company after 2011 (5\%) compared with before 2009 (5\%) (Table 2).

Specifically for the 956 patients treated as outpatients in the United States after 2011, Tables 5 and 6 present their outpatient release, lodging, and transportation data. Twenty-nine percent (211/734) of respondents were administered at least $5.5 \mathrm{GBq}(150 \mathrm{mCi})$ as an outpatient, with $6 \%$ (43/734) administered over $7.4 \mathrm{GBq}(200 \mathrm{mCi})$. ${ }^{131}$ I was administered in a hospital facility $88 \%$ (798/902) of the time. More patients were discharged within $30 \mathrm{~min}$ after receiving ${ }^{131} \mathrm{I}$ therapy after 2011 (78\%; 732/941) than before 2009 (72\%; 768/1,071; $P=0.002$ ) (Table 5).

Approximately $98 \%$ of patients traveled by private car after being released from the treatment facility, and the same percentage of patients traveled more than $2 \mathrm{~h}$ with at least 2 occupants in the vehicle

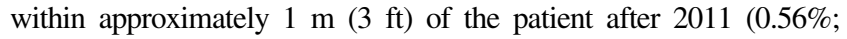
5/898), compared with before 2009 (0.56\%; 6/1067). Immediately after therapy, more patients went to a private residence after 2011 (96\%; 857/953) than before 2009 (94\%; 1,059/1,125; $P<0.001)$, and

\section{TABLE 1}

Demographics of All Respondents

\begin{tabular}{|c|c|c|c|c|c|}
\hline \multirow[b]{2}{*}{ Question } & \multicolumn{2}{|c|}{$1997-2009(n=1,258)$} & \multicolumn{2}{|c|}{$2011-2018(n=1,111)$} & \multirow[b]{2}{*}{$P$} \\
\hline & $n$ & $\%$ & $n$ & $\%$ & \\
\hline Sex & & & & & 0.954 \\
\hline Total answers & 1,250 & & 1,105 & & \\
\hline Female & 1,141 & 91.28 & 1,008 & 91.22 & \\
\hline Age at ${ }^{131}$ I therapy $(\mathrm{y})$, mean \pm SD & $44 \pm 11$ (range, $18-85$ ) & - & $45 \pm 12$ (range, $18-80)$ & - & 0.004 \\
\hline Level of education & & & & & 0.014 \\
\hline Total answers & 1,253 & & 1,066 & & \\
\hline Elementary school & 0 & $0.00 \%$ & 0 & $0.00 \%$ & \\
\hline Middle school & 2 & $0.16 \%$ & 2 & $0.19 \%$ & \\
\hline High school & 253 & $20.19 \%$ & 156 & $14.63 \%$ & \\
\hline College & 662 & $52.83 \%$ & 613 & $57.50 \%$ & \\
\hline Graduate school & 336 & $26.82 \%$ & 295 & $27.67 \%$ & \\
\hline
\end{tabular}


TABLE 2

131| Therapies in All Respondents

\begin{tabular}{|c|c|c|c|c|c|}
\hline \multirow[b]{2}{*}{ Question } & \multicolumn{2}{|c|}{$1997-2009(n=1,258)$} & \multicolumn{2}{|c|}{$2011-2018(n=1,111)$} & \multirow[b]{2}{*}{$P$} \\
\hline & $n$ & $\%$ & $n$ & $\%$ & \\
\hline${ }^{131}$ I therapies & & & & & $<0.001$ \\
\hline Total answers & 1,258 & & 1,107 & & \\
\hline 1 & 893 & $70.99 \%$ & 898 & $81.12 \%$ & \\
\hline 2 & 252 & $20.03 \%$ & 154 & $13.91 \%$ & \\
\hline 3 & 74 & $5.88 \%$ & 37 & $3.34 \%$ & \\
\hline 4 & 21 & $1.67 \%$ & 9 & $0.81 \%$ & \\
\hline 5 or more & 18 & $1.43 \%$ & 9 & $0.81 \%$ & \\
\hline Most recent ${ }^{131}$ I therapy activity & & & & & $<0.001$ \\
\hline Total answers & 872 & & 858 & & \\
\hline$<1.11 \mathrm{GBq}(<30 \mathrm{mCi})$ & 51 & $5.86 \%$ & 30 & $3.50 \%$ & \\
\hline $1.11-1.8 \mathrm{GBq}(30-49 \mathrm{mCi})$ & 43 & $4.94 \%$ & 73 & $8.51 \%$ & \\
\hline 1.85-2.74 GBq (50-74 mCi) & 48 & $5.51 \%$ & 77 & $8.97 \%$ & \\
\hline 2.78-36.6 GBq (75-99 mCi) & 71 & $8.15 \%$ & 85 & $9.91 \%$ & \\
\hline 3.7-5.51 GBq (100-149 mCi) & 293 & $33.64 \%$ & 308 & $35.90 \%$ & \\
\hline 5.55-7.36 GBq (150-199 mCi) & 268 & $30.77 \%$ & 207 & $24.13 \%$ & \\
\hline 7.4-9.2 GBq (200-249 mCi) & 60 & $6.89 \%$ & 36 & $4.20 \%$ & \\
\hline $9.25-11.06 \mathrm{GBq}(250-299 \mathrm{mCi})$ & 16 & $1.84 \%$ & 16 & $1.86 \%$ & \\
\hline$\geq 11.1 \mathrm{GBq}(\geq 300 \mathrm{mCi})$ & 21 & $2.41 \%$ & 10 & $1.17 \%$ & \\
\hline Type of treatment facility & & & & & 0.336 \\
\hline Total answers & 1,247 & & 1,045 & & \\
\hline Outpatient nonhospital & 133 & $10.67 \%$ & 104 & $9.95 \%$ & \\
\hline Community hospital, small & 115 & $9.22 \%$ & 87 & $8.33 \%$ & \\
\hline Community hospital, large & 652 & $52.29 \%$ & 588 & $56.27 \%$ & \\
\hline University hospital & 334 & $26.78 \%$ & 261 & $24.98 \%$ & \\
\hline Veterans Administration hospital & 6 & $0.48 \%$ & 3 & $0.29 \%$ & \\
\hline Military hospital & 7 & $0.56 \%$ & 2 & $0.19 \%$ & \\
\hline Decision on inpatient/outpatient ${ }^{131}$ I therapy ${ }^{*}$ & & & & & $<0.001$ \\
\hline Total answers & 1,248 & & 1,098 & & \\
\hline Prescribed activity of ${ }^{131} \mathrm{I}<1.22 \mathrm{GBq}(<33 \mathrm{mCi})$ & 104 & $8.33 \%$ & 38 & $3.46 \%$ & \\
\hline Physician made decision & 947 & $75.88 \%$ & 577 & $52.55 \%$ & \\
\hline Patient was involved in decision & 141 & $11.30 \%$ & 147 & $13.39 \%$ & \\
\hline Inpatient 131 I therapy was not authorized by insurance & 67 & $5.37 \%$ & 55 & $5.01 \%$ & \\
\hline Patient completed questionnaire on current living situation & 275 & $22.04 \%$ & 32 & $2.91 \%$ & \\
\hline No discussion & 563 & $45.11 \%$ & 474 & $43.17 \%$ & \\
\hline Worry about radiation exposure & & & & & $<0.001$ \\
\hline Total answers & 1,189 & & 1,108 & & \\
\hline 1, none/negligible & 192 & $16.15 \%$ & 104 & $9.39 \%$ & \\
\hline 2, little worried & 172 & $14.47 \%$ & 388 & $35.02 \%$ & \\
\hline 3 , moderate/nervous/anxious & 308 & $25.90 \%$ & 418 & $37.73 \%$ & \\
\hline 4 , high/really worried & 237 & $19.93 \%$ & 167 & $15.07 \%$ & \\
\hline 5 , very high/panicked & 280 & $23.55 \%$ & 31 & $2.80 \%$ & \\
\hline
\end{tabular}

*More than 1 answer was possible for this question. 
TABLE 3

Timing and Personnel for Radiation Safety Discussion, Instructions, and Patient Compliance

\begin{tabular}{|c|c|c|c|c|c|}
\hline \multirow[b]{2}{*}{ Question } & \multicolumn{2}{|c|}{ 1997-2009 } & \multicolumn{2}{|c|}{ 2011-2018 } & \multirow[b]{2}{*}{$P$} \\
\hline & $n$ & $\%$ & $n$ & $\%$ & \\
\hline \multicolumn{6}{|l|}{ When was radiation safety first discussed? } \\
\hline Total answers & Not asked & & 563 & & \\
\hline When ${ }^{131}$ I therapy appointment was made & & & 380 & $67.50 \%$ & \\
\hline On day of ${ }^{131}$ I therapy but before ${ }^{131}$ I was administered & & & 161 & $28.60 \%$ & \\
\hline After ${ }^{131}$ I therapy & & & 7 & $1.24 \%$ & \\
\hline Never & & & 15 & $2.66 \%$ & \\
\hline \multicolumn{6}{|l|}{ Who held radiation safety discussion?* } \\
\hline Total answers & Not asked & & 568 & & \\
\hline Doctor who referred for ${ }^{131}$ I therapy & & & 280 & $49.30 \%$ & \\
\hline Staff at ${ }^{131}$ I treatment facility & & & 456 & $80.28 \%$ & \\
\hline ThyCa & & & 35 & $6.16 \%$ & \\
\hline Other & & & 41 & $7.22 \%$ & \\
\hline \multicolumn{6}{|c|}{ Opportunity to adjust instructions based on patient's current situation? } \\
\hline Total answers & Not asked & & 473 & & \\
\hline Yes & & & 315 & $66.60 \%$ & \\
\hline \multicolumn{6}{|l|}{ When were RSIs delivered?* } \\
\hline Total answers & Not asked & & 564 & & \\
\hline Before day of ${ }^{131}$ I therapy & & & 418 & $74.11 \%$ & \\
\hline On day of ${ }^{131}$ I therapy but before ${ }^{131}$ I was administered & & & 419 & $74.29 \%$ & \\
\hline After ${ }^{131} \mid$ therapy & & & 105 & $18.62 \%$ & \\
\hline Never & & & 7 & $1.24 \%$ & \\
\hline Who orally delivered RSIs?* & & & & & $<0.001$ \\
\hline Total answers & 1,225 & & 1,084 & & \\
\hline Nuclear medicine physician & 656 & $53.55 \%$ & 468 & $43.17 \%$ & \\
\hline Radiation oncologist or radiation therapist & 236 & $19.27 \%$ & 112 & $10.33 \%$ & \\
\hline Endocrinologist & 286 & $23.35 \%$ & 268 & $24.72 \%$ & \\
\hline Nuclear medicine staff (e.g., nurse or technologist) & 422 & $34.45 \%$ & 656 & $60.52 \%$ & \\
\hline Radiation safety staff (e.g., physicist or technologist) & 212 & $17.31 \%$ & 167 & $15.41 \%$ & \\
\hline Nurse & 171 & $13.96 \%$ & 104 & $9.59 \%$ & \\
\hline Administrator & 22 & $1.80 \%$ & 14 & $1.29 \%$ & \\
\hline Other & 21 & $1.71 \%$ & 34 & $3.14 \%$ & \\
\hline Patient signature on form declaring compliance? & & & & & 0.1022 \\
\hline Total answers & 982 & & 843 & & \\
\hline Yes & 861 & $87.68 \%$ & 717 & $85.05 \%$ & \\
\hline Self-assessment of overall compliance & & & & & $<0.001$ \\
\hline Total answers & 1,194 & & 1,105 & & \\
\hline Complete & 1,013 & $84.84 \%$ & 1,034 & $93.57 \%$ & \\
\hline Almost complete & 167 & $13.99 \%$ & 67 & $6.06 \%$ & \\
\hline Half & 9 & $0.75 \%$ & 2 & $0.18 \%$ & \\
\hline Almost none & 3 & $0.25 \%$ & 2 & $0.18 \%$ & \\
\hline None & 2 & $0.17 \%$ & 0 & $0.00 \%$ & \\
\hline
\end{tabular}

*More than 1 answer was allowed for this question. 
TABLE 4

RSIs Given to Patients for ${ }^{131}$ I Therapy

\begin{tabular}{|c|c|c|c|c|}
\hline \multirow[b]{2}{*}{ RSIs } & \multicolumn{2}{|c|}{$1997-2009$} & \multicolumn{2}{|c|}{$2011-2018$} \\
\hline & Oral & Written & Oral & Written \\
\hline Received oral or written RSIs & $97.56 \%(1,198 / 1,228)$ & $95.73 \%(1,144 / 1,195)$ & $95.23 \%(1,039 / 1,091)$ & $90.47 \%(987 / 1,091)$ \\
\hline $\begin{array}{l}\text { To reduce to as low as is reasonably } \\
\text { achievable any radiation exposure } \\
\text { from }{ }^{131} \text { to other individuals }\end{array}$ & $96.56 \%(1,179 / 1,221)$ & $93.86 \%(1,101 / 1,173)$ & $96.34 \%(1,053 / 1,093)$ & $91.70 \%(972 / 1,060)$ \\
\hline $\begin{array}{l}\text { To discontinue breast feeding } \\
\text { (if applicable) and be aware of } \\
\text { potential consequences of } \\
\text { noncompliance }\end{array}$ & $90.66 \%(359 / 396)$ & $87.61 \%(396 / 452)$ & $91.04 \%(183 / 201)$ & $87.96 \%(190 / 216)$ \\
\hline $\begin{array}{l}\text { To be aware of detectable amounts } \\
\text { of }{ }^{131} \text { I that may set off security } \\
\text { alarms at places such as airports }\end{array}$ & $72.40 \%(837 / 1,156)$ & $69.82 \%(768 / 1,100)$ & $76.97 \%(792 / 1,029)$ & $73.41 \%(704 / 959)$ \\
\hline $\begin{array}{l}\text { To keep the name and telephone } \\
\text { number of person or department } \\
\text { to call if any questions about }{ }^{131} \text { I } \\
\text { treatment }\end{array}$ & $72.72 \%(829 / 1,140)$ & $76.42 \%(846 / 1,107)$ & $59.98 \%(586 / 977)$ & $69.95 \%(668 / 955)$ \\
\hline $\begin{array}{l}\text { To not travel by mass transportation } \\
\text { for at least first days }\end{array}$ & & & \multicolumn{2}{|c|}{$82.90 \%(727 / 877)$} \\
\hline $\begin{array}{l}\text { To sleep alone in room for at least } \\
\text { first night }\end{array}$ & & & \multicolumn{2}{|c|}{$97.70 \%(933 / 955)$} \\
\hline To live alone for at least first $2 \mathrm{~d}$ & & & \multicolumn{2}{|c|}{$68.88 \%(686 / 996)$} \\
\hline $\begin{array}{l}\text { To have few visits by family or } \\
\text { friends for at least first } 2 \mathrm{~d}\end{array}$ & & & \multicolumn{2}{|c|}{$87.16 \%(869 / 997)$} \\
\hline $\begin{array}{l}\text { To maintain good distance from } \\
\text { others for at least first } 2 \mathrm{~d}\end{array}$ & & & \multicolumn{2}{|c|}{$97.03 \%(980 / 1,010)$} \\
\hline $\begin{array}{l}\text { To not travel on long car trips with } \\
\text { others for at least first } 2 \mathrm{~d}\end{array}$ & & & \multicolumn{2}{|c|}{$88.97 \%(871 / 979)$} \\
\hline $\begin{array}{l}\text { To not share bathroom for at least } \\
\text { first } 2 \mathrm{~d}\end{array}$ & & & \multicolumn{2}{|c|}{$91.47 \%(912 / 997)$} \\
\hline $\begin{array}{l}\text { To drink plenty of water for at least } \\
\text { first } 2 \mathrm{~d}\end{array}$ & & & \multicolumn{2}{|c|}{$93.58 \%(918 / 981)$} \\
\hline
\end{tabular}

The last 8 RSIs were not available in the 1997-2009 survey.

a similar percentage of patients stayed in a nonprivate residence after 2011 (4\% [35/953] vs. 5\% [52/1,125]; $P=0.28)$.

\section{Outpatients Who Stayed at Nonprivate Residences}

Thirty-five adult respondents stayed at a nonprivate location after outpatient ${ }^{131}$ I therapy in the United States. The nonprivate residences included hotels, motels, boarding houses, or other temporary rentals for $92 \%(32 / 35)$ of patients and specialized facilities such as cancer care housing or radioiodine housing for $8 \%(3 / 35)$ of patients. One patient received less than $1.11 \mathrm{GBq}(<30 \mathrm{mCi})$ of ${ }^{131} \mathrm{I}, 11$ received 11.1-36.6 GBq (30-99 mCi), 18 received 3.7-18.5 GBq (100-499 $\mathrm{mCi}$ ), and 5 patients were unsure of the activity they received.

Of these 35 patients released to nonprivate residences, $77 \%$ (27/35) were released within $30 \mathrm{~min}$ after ${ }^{131} \mathrm{I}$ administration. Some of these 27 patients received high activities of ${ }^{131} \mathrm{I}$ : 8 patients received 3.7-5.5 GBq (100-149 $\mathrm{mCi}), 1$ received 5.6-7.4 GBq (150-199 $\mathrm{mCi})$, and 1 received 9.3-11.1 GBq (250-299 $\mathrm{mCi})$.

A subset of these 35 outpatients answered questions about RSIs. The first radiation safety discussion was held in advance of the ${ }^{131} \mathrm{I}$ therapy (e.g., clinic consultation) in $60 \%$ (9/15) of patients, on the day of therapy but before ${ }^{131} \mathrm{I}$ administration in $33 \%(5 / 15)$ of patients, and after the ${ }^{131}$ I therapy in $7 \%(1 / 15)$ of patients. Nine of 15 patients were able to discuss and adjust the RSIs according to their individual situation, and 3 patients stated that they were not given such an opportunity.

\section{DISCUSSION}

This nationwide survey in comparison to the previous study by Gomes-Lima et al. (1) demonstrated improvements in multiple areas in radiation safety for ${ }^{131} \mathrm{I}$ therapy in differentiated thyroid cancer patients. The comparison demonstrated that more patients participated in the discussion of inpatient or outpatient ${ }^{131}$ I therapy, more patients were able to discuss and individualize their RSIs, more patients self-rated as completely compliant with RSIs, and more patients went to a private residence after outpatient ${ }^{131} \mathrm{I}$ therapy. However, improvements are still needed to increase the percentage of patients having radiation safety discussions and receiving RSIs before the day of ${ }^{131}$ I therapy.

\section{Outpatient Versus Inpatient}

This study demonstrated an increase in the proportion of ${ }^{131} \mathrm{I}$ therapies performed as outpatient therapy and that more patients 
TABLE 5

Outpatient Release and Lodging Data

\begin{tabular}{|c|c|c|c|c|c|}
\hline \multirow[b]{2}{*}{ Question } & \multicolumn{2}{|c|}{$1997-2010$} & \multicolumn{2}{|c|}{$2011-2018$} & \multirow[b]{2}{*}{$P$} \\
\hline & $n$ & $\%$ & $n$ & $\%$ & \\
\hline Release time after ${ }^{131} \mid$ administration & & & & & 0.027 \\
\hline Total answers & 1,071 & & 941 & & \\
\hline Immediately (<30 min) & 768 & $71.71 \%$ & 732 & $77.79 \%$ & \\
\hline $30-59 \min$ & 187 & $17.46 \%$ & 130 & $13.82 \%$ & \\
\hline $1-2 \mathrm{~h}$ & 89 & $8.31 \%$ & 50 & $5.31 \%$ & \\
\hline $2-3 \mathrm{~h}$ & 16 & $1.49 \%$ & 19 & $2.02 \%$ & \\
\hline $3-4 \mathrm{~h}$ & 5 & $0.47 \%$ & 3 & $0.32 \%$ & \\
\hline $4-5 \mathrm{~h}$ & 1 & $0.09 \%$ & 5 & $0.53 \%$ & \\
\hline $5-6 \mathrm{~h}$ & 3 & $0.28 \%$ & 0 & $0.00 \%$ & \\
\hline $6-7 \mathrm{~h}$ & 1 & $0.09 \%$ & 2 & $0.21 \%$ & \\
\hline $7-8 \mathrm{~h}$ & 0 & $0.00 \%$ & 0 & $0.00 \%$ & \\
\hline $8 \mathrm{~h}$ or more & 1 & $0.09 \%$ & 0 & $0.00 \%$ & \\
\hline Lodging & & & & & $<0.001$ \\
\hline Total answers & $1,125^{\star}$ & & 953 & & \\
\hline Own home & 955 & $84.89 \%$ & 795 & $89.13 \%$ & \\
\hline Relative's home & 107 & $9.51 \%$ & 62 & $6.95 \%$ & \\
\hline Motel, hotel, rental house, or boarding house & 52 & $4.62 \%$ & 35 & $3.92 \%$ & \\
\hline Nursing home & 1 & $0.09 \%$ & 0 & $0.00 \%$ & \\
\hline Other & 22 & $1.96 \%$ & 61 & $6.84 \%$ & \\
\hline
\end{tabular}

*More than 1 answer was allowed for this question.

were released within $30 \mathrm{~min}$ after administration of ${ }^{131} \mathrm{I}$. This change might be due to more patients being fully compliant with the RSIs based on self-assessment and more patients staying at a private residence immediately after ${ }^{131} \mathrm{I}$ therapy. With higher patient compliance, nuclear medicine physicians may feel more reassured about allowing release of more patients within $30 \mathrm{~min}$ after ${ }^{131}$ I therapy. Grigsby et al. (7), Marriott et al. (8), and de Carvalho et al. (9) have shown that outpatient therapy can be within radiation exposure limits to family members or caregivers. However, there are 2 concerns. First, with such a short release time, there is the potential for regurgitation or emesis resulting in contamination. Second, there is still a small proportion $(0.56 \%)$ of patients who, when traveling after ${ }^{131} \mathrm{I}$ therapy, were within $1 \mathrm{~m}(3 \mathrm{ft})$ of at least 2 individuals for more than $2 \mathrm{~h}$, which is a period of high radiation exposure (8) and would likely exceed the radiation dose limit (10). Perhaps a reasonable option is to monitor the patient in an isolated waiting room for several hours before hospital release.

\section{Lodging}

This survey showed that there has been no apparent change in the percentage of patients who stayed at nonprivate residences after ${ }^{131}$ I therapy after 2011 . Whether an individual should be allowed to reside in a nonprivate residence remains controversial. The criteria for release require that a determination be made that the patient will not expose the lay public to more than $5 \mathrm{mSv}(500 \mathrm{mrem})$ in total effective dose equivalent (11). However, in this study, a small number of patients who received up to $11.1 \mathrm{GBq}(299 \mathrm{mCi})$ of ${ }^{131} \mathrm{I}$ were released within $30 \mathrm{~min}$ to nonprivate residences. Although there are worksheets to estimate radiation exposure $(12,13)$, it is difficult for physicians or radiation safety officers to determine that a patient staying in a nonprivate residence after release from the hospital will not expose others to more than $5 \mathrm{mSv}$.

The dilemma becomes the balance between protecting the patient's right to privacy and protecting the safety of hotel staff and guests. It is controversial to inform staff and guests at nonprivate residences of the patient's radioactivity because doing so contradicts the patient's right to privacy. Therefore, further evaluation is needed of the many factors that might influence the decision about the location of lodging. These factors include the amount of ${ }^{131}$ I activity, the availability and type of transportation, and the type of lodging. By holding the radiation safety discussion earlier and knowing these factors, one can take measures ahead of time to direct patients to private residences or cancer treatment housing. Furthermore, perhaps in addition to the standard set of RSIs provided to patients, a modified set of RSIs may need to be provided to patients staying at nonprivate residences to ensure proper disposal and precautions such as bringing a set of bedsheets or wearing gloves.

\section{Radiation Safety Discussion}

Moreover, this study showed that after $2011,60 \%$ of patients staying at nonprivate residences took part in their first radiation safety discussion when the ${ }^{131}$ I therapy appointment was made (i.e., clinic consultation) and that $20 \%$ of patients stated they were not given an opportunity to adjust the RSIs according to their individual situations. This finding raises the issue of whether the radiation safety discussions are held early enough for the patient and the treatment facility to arrange to keep radiation exposure to the lay public as low as possible or whether different release 
TABLE 6

Outpatient Transportation Data

\begin{tabular}{|c|c|c|c|c|c|}
\hline \multirow[b]{2}{*}{ Question } & \multicolumn{2}{|c|}{$1997-2010$} & \multicolumn{2}{|c|}{$2011-2018$} & \multirow[b]{2}{*}{$P$} \\
\hline & $n$ & $\%$ & $n$ & $\%$ & \\
\hline Mode of transportation & & & & & 0.862 \\
\hline Total answers & 1,079 & & $955^{\star}$ & & \\
\hline Car & 1,053 & $97.59 \%$ & 938 & $98.22 \%$ & \\
\hline Taxi & 13 & $1.20 \%$ & 12 & $1.26 \%$ & \\
\hline Bus & 0 & $0.00 \%$ & 2 & $0.21 \%$ & \\
\hline Train & 1 & $0.09 \%$ & 1 & $0.10 \%$ & \\
\hline Subway & 3 & $0.28 \%$ & 0 & $0.00 \%$ & \\
\hline Airplane & 0 & $0.00 \%$ & 2 & $0.21 \%$ & \\
\hline Other & 9 & $0.83 \%$ & 12 & $1.26 \%$ & \\
\hline Duration of travel & & & & & 0.964 \\
\hline Total answers & 1,079 & & 937 & & \\
\hline$<1 \mathrm{~h}$ & 843 & $78.13 \%$ & 720 & $76.84 \%$ & \\
\hline $1-2 \mathrm{~h}$ & 176 & $16.31 \%$ & 163 & $17.40 \%$ & \\
\hline $2-3 \mathrm{~h}$ & 37 & $3.43 \%$ & 38 & $4.06 \%$ & \\
\hline $3-4 \mathrm{~h}$ & 14 & $1.30 \%$ & 9 & $0.96 \%$ & \\
\hline $4-5 \mathrm{~h}$ & 3 & $0.28 \%$ & 3 & $0.32 \%$ & \\
\hline $5-6 \mathrm{~h}$ & 4 & $0.37 \%$ & 2 & $0.21 \%$ & \\
\hline $6-7 \mathrm{~h}$ & 1 & $0.09 \%$ & 0 & $0.00 \%$ & \\
\hline $7-8 \mathrm{~h}$ & 0 & $0.00 \%$ & 2 & $0.21 \%$ & \\
\hline$>8 \mathrm{~h}$ & 1 & $0.09 \%$ & 0 & $0.00 \%$ & \\
\hline Number of persons within $1 \mathrm{~m}(3 \mathrm{ft})$ & & & & & 0.046 \\
\hline Total answers & 1,067 & & 915 & & \\
\hline 0 & 566 & $53.05 \%$ & 555 & $60.66 \%$ & \\
\hline 1 & 444 & $41.61 \%$ & 335 & $36.61 \%$ & \\
\hline 2 & 35 & $3.28 \%$ & 20 & $2.19 \%$ & \\
\hline 3 & 9 & $0.84 \%$ & 2 & $0.22 \%$ & \\
\hline 4 & 2 & $0.19 \%$ & 0 & $0.00 \%$ & \\
\hline 5 & 1 & $0.09 \%$ & 0 & $0.00 \%$ & \\
\hline 6 & 3 & $0.28 \%$ & 0 & $0.00 \%$ & \\
\hline 7 & 0 & $0.00 \%$ & 0 & $0.00 \%$ & \\
\hline 8 or more & 7 & $0.66 \%$ & 3 & $0.33 \%$ & \\
\hline
\end{tabular}

${ }^{*}$ More than 1 answer was allowed for this question.

decisions are appropriate. Sisson et al. suggested that "it is essential that radiation safety recommendations be discussed with each patient as soon as treatment with ${ }^{131} \mathrm{I}$ is considered" (10). Theoretically, an appropriate set of RSIs cannot be provided without first engaging in the radiation safety discussion and tailoring to the patient's current living situation.

\section{RSIs}

Although slightly more patients reported having received RSIs in the recent survey time frame, a concern is the timing and scope of RSIs (14). This survey demonstrated that a considerable percentage of patients did not receive RSIs until the day of therapy or afterward. This late timing could prevent these patients from preparing to meet the RSIs or from modifying their plans. At our hospital, the nuclear medicine clinic mails to patients a guidebook with general RSIs and an instruction binder with specific RSIs before the clinical consultation and shows an introductory RSI video on the day of the clinic visit. These steps allow the patients to prepare questions on radiation safety that can be discussed during the actual clinical consultation. As a result, adjustments and accommodations can be made in advance. However, we are uncertain whether these measures have influenced the patient compliance rate.

\section{Who Provides RSIs}

Our study suggests that, after 2011, there has been a shift away from delivery of RSIs by nuclear medicine physicians to delivery by other medical staff. We speculate that nuclear medicine staff members may have more time dedicated to delivering RSIs and to discussing these instructions with patients than do nuclear medicine physicians. This speculation may be supported by the observation 
that more patients were able to discuss and individualize the RSIs after 2011. The trend away from physicians and toward staff members in providing patient education may be similar to that observed in diabetes education, for which dedicated educators are more effective (15). This improvement in the quality of RSI delivery may increase patient compliance. However, the cost effectiveness and benefits of this strategy remain to be evaluated.

\section{Limitations}

Compared with the survey of Gomes-Lima et al. (1), our nationwide survey had a similar population of patients because both surveys were sent to the same thyroid cancer support group (ThyCa) of more than 25,000 members. However, our survey study had several limitations. First, the previous survey was targeted to outpatients and may have been an overrepresentation of outpatient respondents. Second, the surveys depended on the respondents' recollection of events. Third, the respondents represented a select group of individuals who are members of ThyCa and, thus, potentially more computer savvy and more likely to be knowledgeable, motivated, and compliant regarding their ${ }^{131} \mathrm{I}$ therapy and radiation safety precautions. Fourth, not all aspects of the patient RSIs, practices, and compliance could be surveyed without the survey's becoming too long, and too long a survey would likewise have increased the survey incompletion rate.

\section{CONCLUSION}

To our knowledge, this was the largest patient-based survey on selected radiation safety aspects of ${ }^{131}$ I therapies since the 2011 NRC publication on patient release. This survey suggested that after 2011, there have been improvements in some practices on release of outpatients, patient travel, and lodging. However, more research is needed to understand why patients stay at nonprivate residences and how to decrease radiation exposure to the lay public from these patients. In addition, this study raises the question of when and by whom RSIs should be delivered to patients who are considering ${ }^{131} \mathrm{I}$ therapy for differentiated thyroid cancer. Future studies are needed to determine the factors or measures that improve patient compliance with RSIs, including a comparison between the effectiveness of delivery by nuclear medicine physicians and the effectiveness of delivery by dedicated staff members.

\section{DISCLOSURE}

This study was underwritten by a very generous donation by Catherine Heron and Albert Schneider. Douglas Van Nostrand is a speaker and consultant for Jubliant DraxImage. No other potential conflict of interest relevant to this article was reported.

\section{ACKNOWLEDGMENTS}

We thank the following individuals for their contribution to the initial survey development: Matthew D. Ringel, MD, Divisions of Endocrinology and Oncology, Ohio State University; Richard J. Vetter, PhD, CHP, Safety and Biophysics, Mayo Clinic; Elizabeth A. Carter, PhD, MPH, Department of Epidemiology and Statistics, MedStar Health Research Institute; and Gauri Khorjekar, MD, Nuclear Medicine, MedStar Washington Hospital Center. We thank Stephen Fernandez, MPH, and Sameer Desale, MS, from the Biostatistics and Biomedical Informatics Department, Medstar Health Research Institute, for statistical consultation. This study was presented as a poster at the 2019 annual meeting of the Society of Nuclear Medicine and Molecular Imaging, Anaheim, CA.

\section{KEY POINTS}

QUESTION: Has there been a change in practice regarding hospital release of differentiated thyroid cancer patients treated with ${ }^{131}$ I since the publication of the NRC Regulatory Issue Summary 2011-01, title 10 , addressing patient release to nonprivate residences?

PERTINENT FINDINGS: This comparison study between 2 surveys showed that more patients went to a private residence after outpatient ${ }^{131}$ | therapy for differentiated thyroid cancer between 2011 and 2018 than between 1997 and 2009, whereas there was no change in the $4 \%-5 \%$ of patients staying in nonprivate residences. Of the outpatients released to nonprivate residences, $78 \%$ were released within 30 min after ${ }^{131}$ I administration and a small number of these patients received high activities of ${ }^{131}$.

IMPLICATIONS FOR PATIENT CARE: Radiation safety discussion and RSIs provided by a dedicated nuclear medicine staff at an earlier time may help increase patient compliance after hospital release.

\section{REFERENCES}

1. Gomes-Lima CJ, Wu D, Kharazi PH, et al. Selected radiation safety aspects including transportation and lodging after outpatient ${ }^{131} \mathrm{I}$ therapy for differentiated thyroid cancer. Thyroid. 2017;27:1558-1565.

2. NRC Regulatory Issue Summary 2011-01 NRC policy on release of iodine-131 therapy patients under $10 \mathrm{CFR} 35.75$ to locations other than private residences. US Nuclear Regulatory Commission website. https://www.nrc.gov/docs/ML1036/ ML103620153.pdf. Published January 25, 2011. Accessed October 22, 2019.

3. Zanzonico PB. Release criteria and other radiation safety considerations for radionuclide therapy. In: Aktolun C, Goldsmith SJ, eds. Nuclear Medicine Therapy. New York, NY: Springer; 2013:409-424.

4. Siegel JA, Silberstein EB. A closer look at the latest NRC patient release guidance. J Nucl Med. 2008;49(7):17N-20N.

5. Amdur RJ, Snyder G, Mazzaferri EL. Requirements for outpatient release following I-131 therapy. In: Amdur RJ, Mazzaferri EL, eds. Essentials of Thyroid Cancer Management. New York, NY: Springer; 2005:177-182.

6. Harolds JA. New scrutiny of outpatient therapy with I-131. Clin Nucl Med. 2011; 36:206-208

7. Grigsby PW, Siegel BA, Baker S, Eichling JO. Radiation exposure from outpatient radioactive iodine $\left({ }^{131} \mathrm{I}\right)$ therapy for thyroid carcinoma. JAMA. 2000;283: 2272-2274.

8. Marriott CJ, Webber CE, Gulenchyn KY. Radiation exposure for 'caregivers' during high-dose outpatient radioiodine therapy. Radiat Prot Dosimetry. 2007;123:62-67.

9. de Carvalho JW, Sapienza M, Ono C, et al. Could the treatment of differentiated thyroid carcinoma with 3.7 and $5.55 \mathrm{GBq}$ of $\left({ }^{131} \mathrm{I}\right) \mathrm{NaI}$, on an outpatient basis, be safe? Nucl Med Commun. 2009;30:533-541.

10. Sisson JC, Freitas J, McDougall IR, et al. Radiation safety in the treatment of patients with thyroid diseases by radioiodine ${ }^{131} \mathrm{I}$ : practice recommendations of the American Thyroid Association. Thyroid. 2011;21:335-346.

11. $\$ 35.75$ Release of individuals containing unsealed byproduct material or implants containing byproduct material. U.S. Nuclear Regulatory Commission website. https://www.nrc.gov/reading-rm/doc-collections/cfr/part035/part035-0075.html. Updated August 29, 2017. Accessed October 22, 2019.

12. Tuttle WK III, Brown PH. Applying Nuclear Regulatory Commission guidelines to the release of patients treated with sodium iodine-131. J Nucl Med Technol. 2000;28:275-279.

13. Carey JE, Kumpuris TM, Wrobel MC. Release of patients containing therapeutic dosages of iodine-131 from hospitals. J Nucl Med Technol. 1995;23:144-149.

14. Greenlee C, Burmeister LA, Butler RS, Edinboro CH, Morrison SM, Milas M. Current safety practices relating to I-131 administration for diseases of the thyroid: a survey of physicians and allied practitioners. Thyroid. 2011;21:151-160.

15. Grohmann B, Espin S, Gucciardi E. Patients' experiences of diabetes education teams integrated into primary care. Can Fam Physician. 2017;63:e128e136. 